\title{
Igreja eletrônica, religiosidade midiática, religiosidade midiatizada: Conceitos para pensar as relações entre mídia e religião
}

Electronic Church, media religiosity, mediatized religiosity: Concepts to reflect on the relationship between media and religion

\author{
MARCO TÚLIO DE SOUSAa \\ Universidade do Estado de Minas Gerais, Curso de Jornalismo. Divinópolis - MG, Brasil
}

\section{RESUMO}

O crescente número de pesquisas sobre mídia e religião tem favorecido a emergência de um conjunto diverso de olhares sobre o fenômeno, o que se reflete em diferentes metodologias, teorias e conceitos. Este artigo objetiva discutir conceitos recorrentes em trabalhos de pesquisadores desta área, sobretudo no Brasil, e indicar de que modo nos ajudam a entender aspectos dessa problemática, bem como possíveis limitações. Assim, por meio de revisão bibliográfica, reflete-se sobre a produtividade de conceitos gerais como igreja eletrônica, religiosidade midiática, religiosidade midiatizada para pensar as transformações da religião na contemporaneidade nas suas interconexões com a mídia. Palavras-chave: Igreja eletrônica, midiatização da religião, mídia e religião, religiosidade midiática, religiosidade midiatizada

\begin{abstract}
The increasing number of studies on media and religion has favored the emergence of different views on the phenomenon, resulting in different methodologies, theories, and concepts. This paper discusses the recurrent concepts used by researchers in this area, especially in Brazil, showing how they help us understand particular aspects of this problem, as well as its possible limitations. Through a bibliographic review, we reflect on the productivity of general concepts like the electronic church, media religiosity, mediatized religiosity to think on the transformations of contemporary religion in its interconnections with the media.
\end{abstract}

Keywords: Electronic church, mediatization of religion, media and religion, mediatic religiosity, mediatizated religiosity 
${ }^{1}$ Importante notar que o tema tem atraído a atenção de pesquisadores da teologia, ciência da religião, história, sociologia, antropologia, dentre outros, resultando, inclusive, em diálogos profícuos entre as diferentes áreas. Entretanto, tendo em vista a dificuldade de mapear esse amplo território, limitar-nos-emos neste trabalho a listar algumas contribuições de pesquisadores da área em que nos inserimos.

${ }^{2}$ Informação disponível no Diretório de Grupos de Pesquisa do Conselho Nacional de Desenvolvimento Científico e Tecnológico (CNPq). Com o encerramento do grupo, as atividades (reuniões, projetos de pesquisa, realização de eventos etc.) foram remanejadas para o GP Comunicação e Religião da Intercom.

\section{INTRODUÇÃO}

A PUBLICAÇÃO DE TRABALHOS acadêmicos que procuram sistematizar aspectos da produção científica sobre determinado tema 1 sugere que este já adquiriu certo grau de representatividade na comunidade científica. Outras pistas consistem na realização de eventos, formação de associações científicas e grupos de pesquisa, publicação de dossiês em periódicos e criação periódicos científicos especializados na área. Os estudos em comunicação e religião dão sinais de terem alcançado este reconhecimento nos Estados Unidos e na Europa, onde se verifica "a existência de periódicos científicos especializados com mais de dez anos de publicação contínua, como o Journal of Communication and Religion, o Journal of Media and Religion e Journal of Pop Culture and Religion" (Martino, 2012, p. 219). Além destes, podem ser acrescentados o Heidelberg Journal of Religions on the Internet e o Journal of Religion, Media and Digital Culture.

No cenário brasileiro há indícios dessa consolidação. Focando iniciativas do campo acadêmico da comunicação ${ }^{1}$, selecionamos alguns exemplos:

1. Realização eventos: a) Conferência Brasileira de Comunicação Eclesial (Eclesiocom): promovido de 2006 a 2017 pela Cátedra Unesco de Comunicação, da Universidade Metodista de São Paulo (Umesp); b) I Jornada de Mídias e Religiões (2012) e Seminário Internacional de Pesquisas em Midiatização e Processos Sociais (2016, 2018, 2019 e 2020), que tem contado sempre com grupos de trabalho sobre midiatização e religião - ambos foram organizados pelo programa de pós-graduação em Comunicação da Universidade do Vale do Rio dos Sinos (Unisinos) -; c) Congresso Nacional da Intercom que, desde 2018, conta em suas edições anuais com o grupo de pesquisa (GP) Comunicação e Religião (coordenadores: Magali do Nascimento Cunha e Ricardo Alvarenga);

2. Trabalho de grupos de pesquisa, como: Mídia, Religião e Cultura da Umesp (líderes: Magali do Nascimento Cunha e Jorge Miklos; encerrado em $2018^{2}$ ), Circulação midiática e estratégias comunicacionais da UFSM (líderes: Aline Dalmolin e Viviane Borelli), Publicidade nas Novas Mídias e Narrativas de Consumo da UFPE (líderes: Karla Patriota e Rogério Covaleski), Comunicação e Religiosidade da UFG (líderes: Luiz Signates e Ângela Moraes), Midiatização e Processos Sociais (líderes: Antonio Fausto Neto e Pedro Gilberto Gomes) e Laboratório de Circulação, Imagem e Midiatização (líder: Ana Paula da Rosa) da Unisinos; 
3. Publicação de dois dossiês pela revista Comunicação e Informação (2015, n. 2, e 2016, n. 2) e um pelo Anuário Unesco/Metodista de Comunicação Regional (2016) e de obras que reúnem coletâneas de textos de diversos pesquisadores, tais como: Mídia e Religião na Sociedade do Espetáculo (Marques de Melo et al., 2007), Mídia e Religião: Entre o Mundo da Fé e o Fiel (Borelli, 2010), Mídias e Religião: A Comunicação e a Fé em Sociedades em Midiatização (Fausto Neto et al. 2013), Mídia, Religião e Cultura: Percepções e Tendências em Perspectiva Global (Belotti \& Cunha, 2016); Mitos, Mídias e Religiões na Cultura Contemporânea (Klein \& Camargo, 2017); Umbanda, Cultura e Comunicação: Olhares e Encruzilhadas (Camargo, 2019) e Comunicação, Linguagens e Religiões (Cunha \& Storto, 2020). Além disso, ressaltamos também o livro Mídia, Religião e Sociedade: Das Palavras às Redes Digitais, de autoria de Luís Mauro Sá Martino, lançado em 2016;

4. Produção de textos que procuram mapear aspectos dos estudos em comunicação e religião (Cunha, 2002, 2009, 2016; P. G. Gomes, 2010; Martino, 2012, 2015, 2016; Patriota et al., 2016).

Os pontos elencados sugerem que o tema comunicação e religião não só tem despertado o interesse de pesquisadores de diversos programas de pós-graduação em comunicação do país, como também tem levado a movimentos que visam à consolidação de espaços de diálogo. Desse modo, não se trata mais de investigações pontuais de um ou outro(a) pesquisador(a), mas sim da constituição de arranjos que confluem no sentido de fomentar a discussão e promover estabilidade e visibilidade ao tema como objeto de pesquisa científica.

Este artigo se soma aos esforços de sistematização indicados no último tópico. Na esteira do que já foi feito, principalmente, por Assmann (1986), Cunha (2002, 2009), P. G. Gomes (2010) e Martino (2016), serão apresentados e discutidos termos recorrentes utilizados para compreensão de problemáticas referentes às articulações entre mídia e religião focando em três conceitos gerais: igreja eletrônica, religiosidade midiática e religiosidade midiatizada ${ }^{3}$.

\section{IGREJA ELETRÔNICA: UM CONCEITO E (OU) UMA EXPRESSÃO DA RELIGIÃO NA MÍDIA}

O termo igreja eletrônica é um dos mais antigos e o que inicialmente se tornou mais popular na academia e na imprensa para se referir a iniciativas religiosas cristãs na televisão. Deriva da expressão igreja elétrica, oriunda da
${ }^{3}$ É importante aqui fazer uma diferenciação entre religiosidade e religião. Geralmente, o termo religião é empregado para fazer referência à dimensão institucional, que comporta doutrinas, rituais e normas firmadas por uma organização. Já a religiosidade diz respeito ao âmbito experiencial e pragmático na vida dos fiéis, referindo-se ao modo como eles negociam com a oferta (simbólica, prática etc.) das instituições (N. S. Gomes et al., 2014; Rodrigues, 2019). Pode-se, ainda, falar em espiritualidade, o que equivale a "qualquer prática humana que mantém contato entre o mundo cotidiano e um quadro metaempírico mais geral de significado por meio da manipulação individual de sistemas simbólicos" (Hanegraaff, 2017, p. 406), estejam estes ligados ou não a uma instituição religiosa estabelecida. O conceito de religiosidade está contido na concepção de espiritualidade, correspondendo a um tipo de espiritualidade ligada a uma instituição religiosa já existente. A espiritualidade, por sua vez, pode ou não independer de uma instituição religiosa. Como exemplo de espiritualidade não institucionalizada Hanegraaff (2017) cita o movimento Nova Era. Neste artigo, utiliza-se preferencialmente o termo religiosidade na formulação dos conceitos, visto que ele preserva relação com a esfera organizacional, mas não se restringe a ela. Recorre-se ao termo religião para enfatizar aspectos institucionais ou no sentido de fato social, uso corrente entre pesquisadores desse campo de estudos. Pretende-se explorar essas distinções em textos futuros. 
${ }^{4}$ No original: "continuation authentique et miraculeuse de l'Église du Nouveau Testament". Esta e demais traduções, do autor.

\footnotetext{
${ }^{5}$ No original: "A de rares exceptions près, écrit-il, les principaux "ministères" à la télévision aux Etats-Unis sont 1) financés par les dons des auditeurs, 2) organisés autour d'une personnalitévedette, 3) authentifiés par les expériences provoquées, 4) mis au bénéfice des techniques les plus raffinées, 5) conçues pour divertir et 6) marquées par l'esprit de conquête".
}

${ }^{6}$ Segundo Campos (1995), a atuação dos pregadores itinerantes e os camp meetings também podem ser considerados precursores do movimento pentecostal, que surge na primeira década do século XX. obra The Eletric Church, publicada em 1979, nos Estados Unidos, por Ben Armstrong, ex-presidente da National Religious Broadcast, associação criada por grupos religiosos com presença na mídia a fim de defender seus interesses junto aos órgãos públicos estadunidenses. Armstrong via a igreja eletrônica a partir de um interesse religioso de cunho missionário, vindo a classificá-la como uma "continuação autêntica e miraculosa da Igreja do Novo Testamento" (Barka, 2000, p. 32).

Já Schultze, analisando pelo viés acadêmico, define-a a partir de seis características principais:

Com raras exceções, escreve ele, os principais ministros [pastores/padres] na televisão dos Estados Unidos são: 1) financiados pelas doações dos espectadores, 2) organizados em torno de uma personalidade, 3) autenticados pelas experiências que provocam, 4) usam técnicas refinadas, 5) são concebidos para divertir e, 6) marcados pelo espírito de conquista ${ }^{5}$. (Schultze, 1991, p. 28, citado por Barka, 2000, p. 31)

Além dos pontos indicados por Schultze, outro aspecto comum às emissões religiosas consiste nas interpretações de caráter fundamentalista da Bíblia (Cunha, 2002, p. 5). O conceito de igreja eletrônica se relaciona diretamente ao contexto norte-americano e às ações dos chamados televangelistas (líderes religiosos que tinham a televisão como veículo preferencial para suas iniciativas no campo midiático), entre as décadas de 1950 e 1980 . Nesse período, representantes do mundo protestante como Billy Graham, Pat Robertson, Oral Roberts, Jerry Falwell e Rex Humbard comandaram programas de sucesso na TV dos Estados Unidos que se expandiram, inclusive, para outros continentes.

O espírito de conquista, a visão fundamentalista da Bíblia e o papel de destaque desempenhado pela liderança carismática encontram antecedentes na atuação de pregadores itinerantes que percorreram os Estados Unidos no século XIX e início do XX realizando encontros de reavivamento tanto no meio urbano, quanto rural (os chamados camps meetings, realizados em grandes tendas) ${ }^{6}$. Outra fonte que pode ter inspirado os televangelistas foram os programas radiofônicos apresentados por religiosos.

As primeiras incidências da religião em uma emissora de rádio estadunidense se verificam em 1912 quando, a título experimental, transmite-se um ofício religioso natalino em Massachusetts. No entanto, apenas na década seguinte se verifica um crescente interesse por parte de padres e pastores por esse meio de comunicação. Em 1920 é criada a primeira estação de rádio comercial, a KDKA, em Pittsburgh. No ano seguinte, ela já contava com um programa em que era 
transmitido o culto dominical de uma igreja local, atração que foi sucesso imediato (Gutwirth, 1998, p. 17).

O rádio se expande rapidamente pelo país levando consigo a religião. Em 1925 , cerca de sessenta estações de rádio americanas (10\% do total) pertenciam a igrejas ou instituições ligadas a elas. A expansão seria freada em 1927 com a criação Federal Radio Comission (FRC), órgão governamental que regulamentou o sistema de radiodifusão nos Estados Unidos. As altas taxas de impostos levaram muitas rádios religiosas a falir. Em 1933, apenas 33 delas permaneciam operando (Gutwirth, 1998, p. 17).

Isso fez com que muitas igrejas migrassem seus programas para rádios generalistas. O processo foi facilitado devido a uma norma da FRC que obrigava as rádios a colocarem no ar programas de interesse geral, o que abria uma brecha para inserção de programas religiosos de forma gratuita. Todavia, as empresas privilegiavam a cessão de espaço para as tradicionais igrejas protestantes históricas e para a Igreja Católica Apostólica Romana. Isso obrigou pregadores fundamentalistas e suas instituições a comprarem horários na grade de programação e pedirem doações durante as transmissões para a manutenção dessas iniciativas. Dependentes do financiamento da audiência, os pastores são incitados a criar programas mais atrativos, fórmula que depois é copiada pelos televangelistas. Enquanto isso, as beneficiárias dos horários gratuitos persistiram no formato semelhante aos cultos/missas e prédicas bíblicas (Gutwirth, 1998, p. 18).

Nesse período de consolidação do radioevangelismo, algumas figuras sobressaem, como Aimée McPerson (fundadora da Igreja do Evangelho Quadrangular), Charles Fuller e os clérigos católicos Charles Coughlin e Fulton Sheen. Os dois primeiros nomes são considerados precursores imediatos dos televangelistas. Com destaque para Aimée, cuja relação com a música e o desempenho como apresentadora prenuncia nomes como Oral Roberts e Jimmy Swaggart, que também atuaram no rádio. Além deles, outras personalidades da igreja eletrônica, como Graham, Falwell e Robertson, também comandaram emissões radiofônicas, inclusive concomitantemente aos projetos na TV.

Apesar da atuação no rádio, é sobretudo pela televisão que tais figuras alcançam notoriedade. Como já mencionado, seus programas tinham em comum a centralidade na figura do televangelista (em detrimento da instituição religiosa), a autenticação pela experiência do espectador, o uso de técnica refinada, sua concepção voltada ao entretenimento, o financiamento pelo público, o espírito de conquista e a interpretação fundamentalista dos preceitos bíblicos (Cunha, 2002; Schultze, 1991, citado por Barka, 2000). Não obstante, as ênfases na pregação variavam. 
Rex Humbard centrava a mensagem na família: sua família participava dos programas e cantava em conjunto - música era destaque na programação. Ele não era explícito quanto a posições político-ideológicas e pregava a prosperidade econômico-financeira como bênção divina. Jimmy Swaggart também explorava seu dom musical: tinha muitos discos gravados e os apresentava nos programas. Explorava também a retórica com longas pregações com intensa expressão corporal e emocional. Havia espaço na programação para cursos bíblicos e aulas doutrinárias, quando atacava fortemente as igrejas cristãs. . . Pat Robertson foi o que teve menor presença no Brasil. Seu programa era, na maior parte, de entretenimento, um programa religioso de variedades, com forte ênfase na política neoconservadora norte-americana - um exemplo foi a campanha aberta pró-Ronald Reagan. (Cunha, 2002, p. 5)

O termo igreja eletrônica foi formulado inicialmente para dar conta do televangelismo norte-americano. Em estudos acadêmicos posteriores, encontram-se trabalhos que o preservam, mas ampliam sua abrangência (Martín-Barbero, 1995), e outros em que é considerado insuficiente tanto para a problemática relativa ao contexto dos televangelistas (Assmann, 1986) quanto a desdobramentos outros das relações entre mídia e religião (Cunha, 2002). Atentemo-nos ao primeiro ponto.

Martín-Barbero (1995) discute a questão da secularização na América Latina, argumentando que, ao adentrar os espaços midiáticos, as religiões se remagicizam, abrindo possibilidade de reencantamento da vida cotidiana, o que contrariaria, portanto, a tendência de crescente desencantamento do mundo, conforme postula a teoria da secularização de autores europeus e norte-americanos. Ao utilizar o termo igreja eletrônica, o autor faz referência a suas filiações históricas, mas expande a sua aplicação para além do seu contexto inicial.

${ }^{7}$ No original: "Entiendo por iglesia electrónica, el fenómeno que se inició en Estados Unidos extendiéndose por América Latina principalmente a través de las iglesias pentecostales, y su uso más intensivo de los medios masivos constituyéndose en una 'revolución cultural' por lo que implica el paso de millones de gentes a las sectas protestantes, de millones de católicos al mundo protestante, y sobre todo al mundo de las iglesias más fundamentalistas como las pentecostales".
Entendo por igreja eletrônica, o fenômeno que se iniciou nos Estados Unidos se estendendo pela América Latina principalmente através das igrejas pentecostais, e seu uso mais intensivo dos meios massivos constituindo-se em uma "revolução cultural" que implicou a passagem de milhões de pessoas às seitas protestantes, de milhões de católicos ao mundo protestante e, sobretudo, ao mundo das igrejas fundamentalistas como as pentecostais7 . (Martín-Barbero, 1995, p. 76)

Martín-Barbero (1995) também propõe uma reflexão que alarga o modo como a igreja eletrônica vinha sendo pensada até então.

Igreja eletrônica então significa o seguinte: algumas igrejas que não se limitam em utilizar os meios de comunicação para fazer mais ampla a audiência de seus 
sermões, não se limitam a usar os meios para fazer maior o espectro de público que atingem [ênfase adicionada]. A meu ver as igrejas eletrônicas são igrejas que tem se convertido especialmente ao meio rádio e ao meio TV, fazendo da TV e do rádio uma mediação fundamental da experiência religiosa [ênfase adicionada]. É dizer, o meio não é simplesmente uma ajuda para amplificar a voz, mas que é um elemento importante, um elemento fundamental do contato religioso, da celebração religiosa, da experiência religiosa [ênfase adicionada] ${ }^{8}$. (p. 76)

O autor, ao pensar a mídia como elemento fundamental da experiência religiosa na contemporaneidade, ultrapassa a visão muito presente nos primeiros estudos acadêmicos de que a igreja eletrônica se decifra pelo entendimento das estratégias mercadológicas utilizadas pelos televangelistas, as quais resultariam em maior visibilidade para eles e suas respectivas instituições. Compreender a igreja eletrônica passa pelo entendimento da constituição da mídia enquanto mediação da religião na contemporaneidade.

Tal como Martín-Barbero, Hugo Assmann (1986), na obra A Igreja Eletrônica e seu Impacto na América Latina (uma das primeiras publicadas no Brasil sobre o tema), também trabalha com uma concepção de igreja eletrônica que não se restringe ao contexto imediato dos televangelistas norte-americanos. Porém, diferentemente dele, vincula o termo a um aspecto específico das produções midiático-religiosas que implica pensar no manejo de técnicas da publicidade. De acordo com o autor, "alguns autores veem um lado positivo nessa terminologia pelo fato de ela, apesar de ser ideológica, insinuar o manejo de técnicas publicitárias [ênfase adicionada] como de fato sucede na quase totalidade dos programas religiosos de TV" (Assmann, 1986, p. 18). Outros autores criticam tal noção, devido ao uso pouco apropriado do termo igreja, tendo em vista que o que se tem não são exatamente igrejas, mas sim a presença de representantes delas na mídia (Assmann, 1986). Apesar de concordar com a crítica, o pesquisador preserva o termo em sua obra.

Já Cunha $(2002,2009)$ faz crítica incisiva, sugerindo a insuficiência do conceito. A argumentação da autora se dá em duas frentes: 1) na demonstração de que o que se convencionou chamar igreja eletrônica não contempla aspectos relacionados à presença da religião na mídia quando se consideram desdobramentos do fenômeno na sociedade brasileira; 2) na contestação da utilização dos termos igreja e eletrônica.

Diferentemente dos Estados Unidos, onde a televisão foi mais procurada, no Brasil o rádio foi adotado como mídia privilegiada pelos religiosos. Isso decorreu dos altos custos das emissões televisivas e do fato de, inicialmente, a Igreja Católica Apostólica Romana e as protestantes históricas, que então
${ }^{8}$ No original: "Iglesia electrónica entonces significa lo siguiente: unas iglesias que no se limitan a utilizar los medios de comunicación para hacer más amplia la audiencia de sus sermones, no se limitan a usar los medios para hacer más ancho el espectro de público al que llegan. A mi ver las iglesias electrónicas son iglesias que se han convertido especialmente al medio radio y al medio TV, haciendo de la $\mathrm{TV}$ y de la radio una mediación fundamental de la experiencia religiosa. Es decir, el medio no es simplemente una ayuda para amplificar la voz sino que es un elemento importante, un elemento fundamental del contacto religioso, de la celebración religiosa, de la experiencia religiosa". 
dispunham de mais recursos financeiros, terem demonstrado pouco interesse na mídia, o que contrasta com as igrejas pentecostais, sobretudo aquelas que surgiram no país a partir das décadas de 1950 e 1960. Essas últimas preferiram investir em programas radiofônicos em função dos menores custos. Outros aspectos específicos de âmbito nacional são apontados por Cunha $(2002,2009)$ :

1. A presença das igrejas (Universal, Católica, Renascer, Mundial, dentre outras) nas rádios e TVs como compradoras de espaços pagos ou detentoras de canais próprios. No contexto norte-americano, a ocupação de espaços se deu mais pela atuação de pregadores que, muitas vezes, se descolavam das suas instituições. Já no Brasil o papel das igrejas foi preponderante e a vinculação com as lideranças era explícita e valorizada;

2. Se até as décadas de 1960 e 1980 os programas de rádio e televisão privilegiavam as pregações, hoje o conteúdo se diversificou, com programas de entretenimento, jornais, clipes musicais, debates, entrevistas, dentre outros. A mídia impressa também acompanha essa tendência, com revistas de variedades voltadas para o público religioso. As mídias religiosas se tornam cada vez mais parecidas com suas correspondentes seculares;

3. O eixo salvação-milagres-coleta de fundos, característico das emissões dos televangelistas americanos, dá lugar à ênfase na pregação da prosperidade econômica como resultado das bênçãos de Deus e à guerra espiritual contra o demônio e seu séquito de anjos caídos, especialmente nos programas de igrejas neopentecostais (Universal, Renascer, Mundial, Internacional da Graça, Bola de Neve etc.). Além disso, temas diversos como depressão, estresse, drogas e crises familiares passam a ser abordados e ter tratamento religioso;

4. Nos anos 1960 e 1980 os programas centravam-se na liderança carismática de um membro do clero. Posteriormente, as lideranças continuaram a ter papel relevante, mas é cada vez mais comum notar a emergência de personalidades que apresentam programas voltados para um público-alvo específico (jovens, crianças, adultos com problemas sentimentais etc.) (Cunha, 2002).

Além desses aspectos de ordem contextual e histórica, a autora discorda do uso dos termos igreja e eletrônica.

A "Igreja” e suas lideranças podem estar sendo expostas na propaganda da Rede Gospel ou da Rede Record mas . . . a ênfase da mensagem transmitida não é na 
"Igreja" e na adesão a ela, mas no cultivo de uma religiosidade que não depende da Igreja, mas que é intimista, autônoma e individualizada. O que se enfatiza não é a Igreja mas a experiência religiosa mediada pelo meio TV ou rádio, isto é, o meio possibilita o cultivo da religiosidade, independente da adesão a uma comunidade de fé [ênfase adicionada]. O termo "Eletrônica" também não reflete o processo vivenciado hoje. Esta noção remete à ideia de "massa" centrada no uso do aparato tecnológico oferecido pelos meios de comunicação eletrônicos para disseminação da mensagem religiosa - e aqui poderíamos destacar também a informática com a oferta de uma infinidade de páginas na Internet de cunho religioso. (Cunha, 2002, p. 18)

Cunha $(2002,2009)$ se aproxima da abordagem Martín-Barbero, a despeito de, ao contrário do autor, abandonar o termo igreja eletrônica. Em perspectiva próxima aos estudos culturais, a autora propõe o conceito de religiosidade midiática.

\section{RELIGIOSIDADE MIDIÁTICA E OUTRAS PROPOSIÇÕES ALTERNATIVAS À IGREJA ELETRÔNICA}

Pode-se dizer que o televangelismo estadunidense foi um dos grandes responsáveis por despertar na academia o interesse em compreender as interações entre mídia e religião (Bruce, 1990, citado por Martino, 2016). Segundo Martino, tal interesse surge primeiro em pesquisas da sociologia da religião na década de 1960, nos quais a mídia ainda figurava como elemento secundário. Nos anos 1980, têm-se as primeiras aproximações da área da comunicação com estudos sobre a comunicação eclesial. A partir da década de 1990, os desenvolvimentos das pesquisas nessa área levam à diversificação nas temáticas" (Martino, 2016, p. 19).

Em um primeiro momento, o campo da comunicação bebe em referenciais sociológicos (principalmente sociologia da religião e teoria crítica). Posteriormente, ocorrem deslocamentos epistemológicos que resultam da criação e desenvolvimento de referenciais teóricos nesse campo e da diversificação dos fenômenos que envolvem mídia e religião, dentre os quais podem-se citar: os investimentos das igrejas neopentecostais e da renovação carismática nas mídias eletrônicas e digitais, bem como as inserções das religiões mediúnicas (Umbanda, Candomblé e Espiritismo Kardecista) nessas mídias (Martino, 2016). De uma visão de mídia por vezes instrumental e que se concentrava, sobretudo, nos efeitos produzidos no público a partir das emissões religiosas, passa-se a 
uma abordagem compreensiva, que procura entender os tipos de experiências e sentidos que se constroem nas articulações do religioso com o midiático.

Ao voltar nossa atenção para as críticas ao conceito de igreja eletrônica, é possível perceber indícios dessa mudança. Embora o foco deste texto sejam as contribuições na área da comunicação, será possível notar na relação de conceitos listados a seguir que os termos alternativos partem de diversas áreas, o que nos revela, por um lado, a riqueza do diálogo interdisciplinar, e, por outro, a dificuldade em situar de maneira precisa as fronteiras e contribuições de cada campo:

1. Religião comercial: defendida por aqueles que acreditam que os "televangelistas não representem autenticamente a Igreja” (Assmann, 1986, p. 19), essa expressão acentua o viés comercial dos programas, muitos dos quais pediam doações e (ou) vendiam produtos. Assmann (1986) critica o conceito, uma vez que nem todos os programas religiosos apresentam tal característica. Pode-se lembrar, por exemplo, das transmissões de cultos e missas, presentes já nas primeiras emissões religiosas no rádio e que também são veiculados na televisão. Outro problema adicional do conceito consiste no fato de se limitar a uma crítica social à atuação dos televangelistas. A nomenclatura foi proposta por William F. Fore, então membro do Conselho Nacional de Igrejas dos Estados Unidos e presidente da World Association for Christian Communication (WACC), em 1983, por não aceitar o uso do termo igreja devido a questões éticas e morais. Logo, tem mais a ver com discussões internas do campo religioso do que, propriamente, com aspectos organizacionais, sociológicos e históricos;

2. Marketing da fé: sugere que os programas religiosos televisivos se pautam em um modelo publicitário no qual a salvação é ofertada como mercadoria: "clima de sugestão - identificação de uma 'necessidade' não suprida - apresentação da 'resposta' - Ato de compra” (Assmann, 1986, p. 20). Apesar de mais bem fundamentado que o anterior por procurar identificar uma lógica comum em tais programas, o termo também tem por desvantagem a generalização no tocante ao aspecto comercial. Sua utilização seria adequada para contextos em que pesquisadores identificam tal lógica em funcionamento. No contexto brasileiro, encontram-se traços desse modelo em programas televisivos de escuta de confissões cristãs transmitidos durante as madrugadas (Fausto Neto, 2004; Sousa, 2014);

3. Messianismo eletrônico: igualmente surgiu como opção à igreja eletrônica. $\mathrm{O}$ caráter messiânico diz respeito às lideranças religiosas 
na mídia e suas promessas de curas, milagres e salvação. Assmann (1986), porém, discorda de tal definição. Segundo ele, "seria realmente uma pena que o conceito bíblico (e inclusive sociológico) de 'messianismo', tão prenhe de esperança e lutas históricas, ficasse aviltado dessa maneira" (Assmann, 1986, p. 21). Além das tensões que pode despertar no meio religioso e em algumas abordagens acadêmicas, como aponta Assmann (1986), trata-se de um termo problemático pela sua limitação a contextos religiosos específicos, notadamente ao âmbito cristão;

4. Assembleia eletrônica: diferentemente dos anteriores, não aparece relacionado ao fenômeno nos Estados Unidos. Manifesta uma preocupação distinta dos demais, sendo mais utilizado no meio intelectual católico com o objetivo de designar a possibilidade de uma experiência comunitária nas transmissões televisivas e radiofônicas das celebrações litúrgicas. Apesar de ainda preservar o problemático significante eletrônica, sua formulação tem a vantagem de ir além da lógica mercadológica que permanece nos anteriores (Assmann, 1986). Preservando o sentido de experiência comunitária via mídia, o conceito poderia se expandir para além do contexto católico e com uma simples substituição de palavras (eletrônica por midiática) perder o teor instrumental. Desse modo, o termo assembleia midiática poderia ser útil em pesquisas que abordem experiências nas quais há interação entre fiéis e aqueles que conduzem os ofícios/ cerimônias/eventos religiosos em ambiente midiático. Não há uma mídia predefinida9.

Os conceitos 1 a 4 são discutidos brevemente em A Igreja Eletrônica e seu Impacto na América Latina, de Asmann (1986), como respostas à concepção de igreja eletrônica. As origens dessas críticas nem sempre são indicadas, mas percebe-se que partem principalmente da teologia e da sociologia da religião, áreas de atuação do autor. Assmann (1986) também faz críticas ao termo, mas revela que prefere deixar em aberto a questão sobre qual formulação seria a mais adequada, visto que ainda havia poucos estudos sobre o fenômeno nos Estados Unidos e na América Latina. Desse modo, preserva o seu uso, mas opta por utilizá-lo entre aspas.

Os próximos termos são encontrados em textos acadêmicos da área da comunicação a partir dos anos 2000. As expressões em 5 e 6 tratam de articulações das religiões com a mídia digital. Já religiosidade midiática (7) desponta como possível substituto de igreja eletrônica.

\footnotetext{
${ }^{9}$ A pandemia da Covid-19 obrigou muitos grupos a migrarem suas atividades religiosas para as mídias (rádio, televisão e, principalmente, internet). Isso criou um cenário rico de experimentações que merecem a atenção da academia.
} 
${ }^{10}$ Não encontramos em textos posteriores da autora publicados em revistas e anais de congressos menções ao conceito de religiosidade midiática, tampouco uma revisão que sugira sua insuficiência. Não obstante, parece-nos evidente que as ideias que embasam suas reflexões acompanham esta concepção discutida nos artigos referenciados (Cunha, 2002, 2009).

${ }^{11}$ Importante notar que o termo também foi utilizado por Hartmann (2002). Entretanto, este autor não propõe uma definição, aplicando-o para diferenciar as ações dos televangelistas brasileiros em relação à igreja eletrônica, que ele associa às ações dos televangelistas americanos.
5. Cyberchurch e igreja virtual: relacionam-se à atuação das igrejas na rede, o que inclui a realização de serviços e ofícios no mundo digital que estavam antes disponíveis apenas presencialmente. Ao analisar as duas expressões, P. G. Gomes (2010) sugere que a primeira é mais adequada, visto que o significante virtual se refere à "experimentação de algo antes que seja configurado como real. . . . Ora, isso não pode ser aplicado à Igreja. Uma assembleia virtual não pode ser experimentada antes" (p. 45);

6. Ciber-religião (Miklos, 2010), religião digital (Cunha, 2016) Religião 2.0 (Patriota \& Freire, 2015): não encontramos definições rígidas que justifiquem a opção dos autores por um termo em detrimento a outro. É comum, inclusive, encontrar mais de um deles como sinônimo em um mesmo texto. São mais abrangentes, não se restringindo ao âmbito institucional cristão, tal como cyberchurch e igreja virtual. A despeito de ser usado como sinônimo dos demais, o termo religião 2.0 parece ter alcance mais específico, voltado a uma fase do desenvolvimento da web (2.0). De forma geral, tais termos designam a presença religiosa no mundo digital e surgem da necessidade de se nomear um fenômeno a partir de objetos específicos analisados pelos autores. $\mathrm{O}$ desenvolvimento das pesquisas pode levar a futuras sistematizações que seriam muito bem-vindas para a área;

7. Religiosidade midiática: conceito proposto por Cunha $(2002,2009)^{10}$ como alternativa ao de igreja eletrônica que a autora considera não dar mais conta das complexas relações que envolvem mídia e religião $^{11}$. Baseando-se em autores ligados aos Estudos Culturais, como Martín-Barbero e Stuat Hall, Cunha $(2002,2009)$ traz à baila a noção cultura midiática, uma resposta crítica à expressão cultura de massa formulada em um contexto acadêmico em que a recepção das maiorias era vista como padronizada e subordinada às intencionalidades da indústria cultural.

A cultura midiática [ênfase adicionada] vai além ao refletir o paradigma da globalização e do consumo: o mercado, atravessando os países, teria se consolidado como uma instância fundamental de produção de sentido [ênfase adicionada]. Neste quadro, as massas não importariam mais, e, sim, o mercado. Na cultura midiática diferença e padronização convivem sincronicamente, pois é no âmbito do mercado, base dessa cultura, que os indivíduos e os grupos sociais constroem suas identidades, partilham expectativas de vida, modos de ser, e o poder se torna virtualizado. (Cunha, 2002, p. 12) 
Segundo a autora, a religiosidade midiática, que emerge atrelada a essa cultura, pode ser observada em várias frentes, tais como: na incorporação dos meios de comunicação de massa aos ritos religiosos, os quais se tornam veículos de promoção de sucessos de bandas gospel; na promoção de bens de consumo religiosos que propiciam ao fiel experimentar a uma só vez a espiritualidade e o lazer, rompendo, no âmbito evangélico, com costumes da tradição; na criação de celebridades que transitam entre o religioso e o entretenimento (Cunha, 2009).

Enquanto conceito geral para se pensar as relações entre mídia e religião, o termo religiosidade midiática é mais proveitoso do que igreja eletrônica, que limita a experiência midiático-religiosa ao âmbito institucional cristão e se relaciona a uma visão de um público subordinado a uma lógica mercantilista. Reconhece-se a atuação do aspecto econômico como integrante dessa realidade, mas não se limita a compreensão do fenômeno pela mera identificação de estratégias mercadológicas. $O$ ponto central nessa perspectiva é a consolidação de uma instância de produção de sentido, de experiência religiosa configurada midiaticamente. Desse modo, Cunha $(2002,2009)$ preserva as contribuições de Martín-Barbero (1995), mas avança a partir dele, na proposição de um conceito que supera as limitações terminológicas e contextuais do de igreja eletrônica.

O conceito de religiosidade midiática tem três vantagens: 1) atualiza a discussão sobre as relações entre mídia e religião; 2) ao incorporar significantes mais flexíveis e abrangentes, abre-nos a possibilidade de pensar fenômenos em que, embora não haja vinculação explícita com uma organização ${ }^{12}$ religiosa ou midiática, há referências ao mundo religioso; 3) sugere a formação e consolidação de formas de cultura religiosa que têm na mídia um de seus elementos definidores.

Outro conceito que tem sido de fundamental importância no desenvolvimento de pesquisas em mídia e religião na área da comunicação surge a partir dos estudos em midiatização.

\section{O conceito de midiatização e a religiosidade midiatizada}

Midiatizada, a religião se transforma. A palavra transformação é crucial para entendermos o conceito de midiatização. A despeito das formulações e aplicações particulares, encontramos um entendimento comum de que

podemos definir a midiatização como o conceito usado para analisar a inter-relação (de longo prazo) entre a mudança da mídia e da comunicação, por um lado, e a mudança da cultura e da sociedade, por outro, de uma maneira crítica. (Hepp, 2014, p. 51)
${ }^{12}$ Daí a utilização do termo religiosidade em vez de religião, que guarda mais proximidade com o âmbito institucional. Nesse sentido, constitui exemplo interessante a tese de doutorado de Iuri Andréas Reblin (2012), em que $\mathrm{o}$ autor analisa aspectos da religiosidade cristã em heróis dos quadrinhos como Superman e Shazam. 


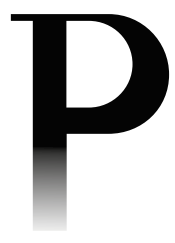

${ }^{13}$ Pode-se questionar se, do ponto de vista da recepção, a escuta do ofício pelo rádio pode ser compreendida como experiência religiosa midiatizada, já que houve mudança no modo de se experimentar o ritual. No entanto, esta discussão extrapola os objetivos deste

texto.

${ }^{14}$ Embora não seja nosso objetivo mapear essa discussão, é importante observar que em 2014 foi publicado um artigo de autoria dos ingleses Deacon e Stanyer em que pontuam críticas às pesquisas em midiatização. Um dos pontos destacados pelos autores é justamente o risco de se deslizar para o midiacentrismo. $\mathrm{O}$ texto levou a uma resposta de Hepp et al. (2015).

Esses autores argumentam, distinguindo o midiacentrismo

da pesquisa midiacentrada que corresponde a um esforço específico desses investigadores

em estudar o papel da mídia sem, contudo, a colocar como condicionadora da sociedade.

${ }^{15}$ É importante notar que diversas abordagens trabalham com o conceito de midiatização. Dentre elas, destacamos três que têm sido acionadas em trabalhos publicados no país: institucionalista, construtivista e semióticodiscursiva interacional. As duas primeiras têm como expoentes autores europeus, como Stig Hjarvard (institucionalista) e

Andreas Hepp (construtivista) e a terceira tem sido

desenvolvida especialmente por pesquisadores latinoamericanos, dentre eles:

Eliseo Verón, Mario Carlón, Ana Paula da Rosa, Viviane Borelli, José Luiz Braga, Jairo Ferreira, Antonio Fausto Neto e Pedro Gilberto Gomes. Não entraremos em mais detalhes visto que isso escapa aos objetivos do artigo.

De modo semelhante, afirma P. G. Gomes (2016) que "a midiatização é usada como um conceito para descrever o processo de expansão dos diferentes meios técnicos e considerar as interrelações entre a mudança comunicativa dos meios e a mudança sociocultural" (p. 1).

Dessa maneira, midiatização não diz respeito simplesmente à presença da mídia na religião. Uma mera transmissão de um ofício religioso pelo rádio ou pela televisão não significa que ele foi midiatizado. "A midiatização tem início no momento em que as mídias ... tornam-se parte das atividades individuais e institucionais. Quando processos sociais assumem novas configurações, ganhando outras formas e contornos, aí se pode pensar em termos de midiatização" (Martino, 2016, pp. 36-37).

As primeiras experiências dos padres e pastores na rádio estadunidense foram marcadas pela mera transposição das prédicas dominicais para esse veículo, o que configura uma prática midiática, mas não necessariamente uma prática midiatizada do ponto de vista da sua produção ${ }^{13}$, visto que não houve transformação no âmbito da linguagem, do modo de se fazer/ser religião. Em um segundo momento, a necessidade de financiamento levou pregadores fundamentalistas a criarem emissões mais atrativas, que incorporavam a linguagem radiofônica na construção da mensagem religiosa. Nesse caso, pode-se falar em midiatização da religião uma vez que se verificou transformação da prática religiosa na sua articulação com o midiático.

Importante frisar que midiatização não corresponde à mera submissão da sociedade a uma (pres)suposta influência midiática, o que levaria ao risco do midiacentrismo ${ }^{14}$, ou seja, de se tomar a mídia como eixo único que determina os processos sociais. Há, na verdade, um intercâmbio entre as "lógicas de mídia" (Hjarvard, 2014) e as lógicas de outros campos sociais mediada pelas ações de operadores do campo e pelos atores sociais que, de maneira conjunta e heterogênea, constroem novas práticas sociais. É neste entremeio que podemos localizar as "lógicas da midiatização" (Braga, 2015). Elas se constituem neste contato, nesta friç̧ão entre as diversas lógicas que ora se sobrepõem, ora se harmonizam, que se agenciam mutuamente e são agenciadas pelas experiências e ações dos atores sociais. Constituem, portanto, percursos espiralizados e multidirecionais em constante reconfiguração, cujo destino não se pode presumir de antemão. Ao analista cabe a assumir postos (o lugar de onde se analisa) e pontos de observação (o que se analisa) e mapear como esses pontos se ligam, se combinam, se articulam a outros no fazer social, vindo a constituir arranjos. Isso significa adotar uma abordagem teórica e uma metodologia mais adequadas às configurações do objeto de pesquisa $\mathrm{e}$ à pergunta que a ele se faz ${ }^{15}$. 
Considerando as interações entre campos e atores sociais na sua relação com a dimensão religiosa (organizações, símbolos, linguagens, crenças etc.), propomos sistematizar os estudos em midiatização da religião e da religiosidade em quatro frentes ${ }^{16}$ que contemplam as seguintes ênfases de pesquisa: 1) o religioso na mídia laica; 2) produções midiáticas de organizações religiosas; 3) a participação da mídia (e do campo midiático) na interação do campo religioso com outros campos sociais; 4) o religioso na produção midiática dos indivíduos e agrupamentos formados por eles na internet. É importante notar que não se tem por objetivo propor uma classificação rígida pela qual as investigações são alocadas em uma ou outra vertente. Fazer isso contraria a natureza heterogênea das pesquisas e seus atravessamentos mútuos. Trata-se de uma proposta de organização que permite identificar tendências e interesses dos pesquisadores no que tange ao processo de midiatização da religião e da religiosidade:

1. Mídia laica $\rightarrow$ religioso. Reflete-se, sobretudo, sobre produções midiáticas ficcionais e não ficcionais que constroem narrativas em que figuram personagens, personalidades, instituições do mundo religioso existente ou ficcional ou, ainda, estabelecem um universo religioso próprio em suas tramas. As investigações dão a ver formas de contato com o religioso alheias às organizações religiosas. Em pesquisa feita na Dinamarca, Hjarvard observa que houve crescimento na quantidade de conteúdo religioso na mídia a partir da década de 1990, o que inclui desde produções ficcionais a programas televisivos que abordam o paranormal, o sobrenatural ou problemáticas institucionais das religiões (Hjarvard, 2006). Citando Jenkins, afirma que as "fan cultures" chegam a ter muitos aspectos semelhantes aos de grupos religiosos, apesar dos distintos "objetos de adoração". Outro aspecto destacado pelo autor é o papel da mídia laica na atualização e recriação de rituais como casamentos e funerais, podendo disputar ou compartilhar interesses com as igrejas. A investigação o leva a concluir que, embora não haja um impacto uniforme, a midiatização pode fazer com que se fale em ressacralização da sociedade pela mídia, perda da autoridade institucional das religiões e promoção de rituais cada vez mais secularizados (Hjarvard, 2006). Ainda nessa vertente, pode-se pensar também em análises que identificam configurações simbólicas que se apoiam no religioso, sem explicitá-lo, como o faz Bratosin (2004) ao analisar a construção de uma representação mítica nas comunicações públicas do ex-presidente francês Jacques Chirac por meio do uso do significante concertação (concertation);
${ }^{16}$ Partimos inicialmente da proposta de Martino (2012), que identifica três tendências: 1) a religiosidade na mídia laica; 2) as produções midiáticas de organizações religiosas; 3 ) a discussão sobre midiatização e secularização. 
2. Mídia religiosa $\rightarrow$ religioso. Volta-se para o modo como as organizações religiosas se apropriam da mídia. A midiatização aparece aqui a partir das ações das próprias organizações que veem na mídia um espaço estratégico. Procura-se observar as implicações para as instituições religiosas, seu público interno (fiéis) e externo (não fiéis). Pensa-se sobre a produção ou/e recepção de tais produções midiáticas. Pesquisas nessa área têm refletido a respeito da reconfiguração da linguagem religiosa e de seus rituais a partir de discursos que, a despeito de suas nuances particulares (mais ou menos conversionistas), levam em conta estratégias tecnodiscursivas que primam pelo afeto, pela emoção e pela criação de pontos de vínculo que compensem a não simultaneidade espacial. Ao analisar produções televisivas católicas e evangélicas na TV brasileira, Fausto Neto (2004) observa que, em comum, desponta nas emissões uma "religiosidade do contato" pela qual a distância física é compensada por uma linguagem que prima pela proximidade seguindo uma dinâmica interacional que se assemelha a de consultórios médicos e psicoterápicos. Sbardelotto (2012), por sua vez, trata da configuração de rituais midiatizados em portais católicos em que é possível, por exemplo, acender uma vela ou rezar o terço on-line. Desse modo, elabora-se "não apenas uma liturgia assistida pela mídia, mas também uma liturgia centrada, vivida, praticada e experienciada pela mídia, em que esta também oferece modelos para as práticas, o espaço e o imaginário litúrgicos" (p. 12). Já a investigação de Sousa (2018a) sobre rituais em programas televisivos da Igreja Universal do Reino de Deus aponta que a midiatização da religião pode instaurar pontos de sacralização da mídia. A benção do copo com água sobre o aparelho televisivo e os exorcismos feitos durante participações por telefone não trazem inovações de linguagens e práticas somente para o campo religioso, instaurando também outras formas de se relacionar com a mídia (inclusive com o seu dispositivo tecnológico) não presentes na mídia laica. Ou seja, a própria mídia é afetada pelas lógicas de midiatização, visto que elas se produzem numa dinâmica de inter-relação do campo midiático com outros campos sociais e não por mera submissão a uma suposta influência da mídia;

3. Campo religioso $\leftarrow$ mídia $\rightarrow$ demais campos sociais. Dedica-se a refletir sobre como o midiático participa nas relações que se estabelecem entre o campo religioso, outros campos e atores sociais. Trabalhos nessa frente tratam de estratégias de ocupação de espaços na mídia e/ou as configurações discursivo-midiáticas que despontam 
dessa ocupação. O religioso e o midiático tornam-se espaços públicos de disputas de poder e de sentido na sociedade. Pesquisas têm destacado, por exemplo, a atuação de organizações religiosas e seus representantes em disputas eleitorais (Damasio, 2020; Martino, 2014), a atuação de parlamentares ligados ao campo religioso e as respectivas reações dos indivíduos na mídia, especialmente nas redes sociais digitais (Marques \& Guimarães, 2018). Isso ocorre não somente quando o campo religioso desloca sua atuação para a esfera pública, ao interferir na configuração de fenômenos e práticas próprias de outros campos sociais, como o político, mas também no sentido inverso. A tese de doutorado de Borelli (2007), ao analisar a midiatização da romaria da Medianeira (Santa Maria, RS) pela Rede Vida de Televisão, constitui interessante exemplo de análise das ações dos campos político, econômico e da segurança pública junto ao campo religioso na configuração de uma romaria midiatizada;

4. Mídias dos indivíduos $\rightarrow$ religiosidade. $\mathrm{O}$ advento da internet e, especialmente, das redes sociais digitais possibilitou aos atores sociais a produção de conteúdo midiático, o que antes ficava restrito às organizações de mídia e entidades com poder financeiro. A internet emerge como um espaço de experimentações e bricolagens no qual os indivíduos buscam modos de se relacionar com o universo religioso. Rituais religiosos são reconfigurados em iniciativas como grupos de oração pelo WhatsApp (Sousa, 2018b) e páginas de grupos no Facebook que abordam a doutrina de uma religião ou temas atuais pela ótica religiosa (Rosa, 2018; Sbardelotto, 2014), favorecendo agrupamentos de sujeitos distantes no espaço físico, mas que comungam de um mesmo interesse ${ }^{17}$. Esse cenário favorece a emergência de lideranças religiosas que não compõem o quadro eclesiástico de uma instituição, mas discutem e fazem com que a religião esteja presente no espaço público. A autoridade religiosa se uberiza (Tudor \& Herteliu, 2017). Tal fenômeno impõe desafios às instituições, que, diante dessa realidade, se veem na necessidade de instaurar novos pontos de contato no espaço público ${ }^{18}$, gerando, inclusive, reflexões no âmbito da teologia, ciberteologias (Spadaro, 2012). Outro desafio se instaura quando da profusão de críticas negativas e campanhas de linchamento digital nas redes sociais digitais. Se antes o gerenciamento das crises pelas organizações religiosas se dava por ações e negociações entre o campo religioso e os demais campos sociais, agora isto transborda para uma infinidade de perfis, inclusive falsos, nas redes sociais digitais. Ou
${ }^{17}$ Cunha (2016) cita a formação de grupos de fiéis "semigreja” (p. 14), pessoas que se consideram religiosas, mas que não pertencem a uma instituição específica, nas redes sociais digitais como um dos fenômenos da religiosidade no ambiente digital.

${ }^{18}$ Em 2017, a Igreja Católica concedeu ao responsável pelo blog e página no Facebook "O Catequista" (administrado por leigos católicos) uma credencial reservada apenas aos jornalistas setoristas que cobrem o Vaticano. Foi a primeira vez em sua história que a instituição concedeu este tipo de autorização a alguém que não mora em Roma (Rosa, 2018) 
seja, a presença na web, ao mesmo tempo que se configura como uma quase obrigação para a sobrevivência de uma organização religiosa no espaço público, fragiliza-a, expondo a si e a suas lideranças à constante vigilância pública dos atores nas redes.

As pesquisas em midiatização chamam a atenção para uma religiosidade em processo, sujeita às injunções dos campos sociais, às ações dos indivíduos e às potencialidades ofertadas pelas tecnologias de comunicação e pelas lógicas próprias do campo midiático. Práticas religiosas midiatizadas configuram novas práticas de sentido, que dizem de um novo modo de se vivenciar a fé na contemporaneidade. As frentes de estudos descritas aclaram aspectos parciais desta transformação social que toca não apenas o religioso e organizações religiosas, mas diz também de mudanças profundas da sociedade.

O conceito de religiosidade midiatizada torna-se fundamental para pensar essa realidade. Não se congela uma realidade ou uma configuração específica do fenômeno, pois a midiatização diz de um objeto dinâmico que flui e parece sempre escapar. Cabe aos pesquisadores a tarefa de captar recortes, realidades parciais, que permitem perceber nas partes o todo que as engendra. Trata-se de um conceito que, tal como o de religiosidade midiática, atualiza a discussão sobre mídia e religião e abre a possibilidade de pensar fenômenos que não se circunscrevem, necessariamente, às ações do campo religioso institucionalizado.

\section{CONSIDERAÇÕES FINAIS}

Nomes são relacionais, são formas de dizer o mundo (Ferrara, 2010). O escolher está implicado na tarefa de nomear de tal modo que, ao dizer o que algo é, deixa-se subtendido o que ele não é. Nomear é circunscrever e delimitar. Conceituar, por sua vez, é nomear uma ideia, é trazer para a esfera da sensibilidade, do reconhecimento, o que caracteriza um fenômeno. De acordo Ferrara (2010),

se o conceito corresponde àquela necessidade disciplinadora e codificadora do mundo, seu nome deve corresponder a uma espécie de registro causal das manifestações do mundo, de modo que acreditamos conhecer através dos nomes que atribuímos às coisas que queremos conhecer [ênfase adicionada]. (pp. 53-54)

Conceitos têm importância estratégica para o fazer ciência não só por aclararem à mente dinâmicas de funcionamento de fenômenos do mundo, mas também pelo seu potencial heurístico, ensejando novas teorizações. Todavia, correm o risco de congelar uma realidade e perder de vista o objeto. O conceito de igreja eletrônica, ainda na década de 1980, teve papel fundamental 
por fornecer uma chave de compreensão para as ações dos radioevangelistas e, principalmente, dos televangelistas, despertando a atenção da sociedade e da comunidade científica para as implicações das relações que se constituíam entre mídias e religiões.

Todavia, o conceito se mostrou problemático já na sua origem em função da associação pouco produtiva dos significantes igreja e eletrônica, o que se pode atribuir, pelo menos em parte, a sua formulação inicial não acadêmica. Uma segunda razão consiste nos desdobramentos posteriores das relações entre mídia e religião no âmbito cristão em que despontaram configurações distintas do modelo de produto midiático centrado na celebridade religiosa e caracterizado pelo manejo de técnicas publicitárias com foco em uma experiência individualizada e intimista (Assmann, 1986; Cunha, 2002). Ainda que MartínBarbero (1995) e Assmann (1986) o apliquem para pensar realidades distintas das dos televangelistas norte-americanos, o nome não dá conta do fenômeno que designa. Essa incompatibilidade sugere que ele deve ser substituído ou, no limite, que seu uso permaneça apenas como referência ao fenômeno do televangelismo estadunidense do século XX.

Nesse cenário, religiosidade midiática e religiosidade midiatizada se apresentam como proposições alternativas à igreja eletrônica. Essas formulações despontam a partir da década de 1990 e dos anos 2000 na área da comunicação, momento em que os objetos e as abordagens teóricas para pensar mídia e religião se diversificam (Martino, 2016). Quando comparados analiticamente com o conceito de igreja eletrônica, observa-se que ambos agrupam significantes mais abertos, não limitando à reflexão ao âmbito institucional cristão. Desse modo, permitem expandir, sem perdas semânticas, a reflexão para outras religiões (budismo, islamismo, hinduísmo, umbanda, candomblé, espiritismo kardecista etc.) e para manifestações que não necessariamente funcionam segundo as prescrições de uma organização religiosa. A utilização do termo religiosidade é estratégica, visto que não se deixa dizer o que é próprio da religião e ao mesmo tempo não se aprisionam os fenômenos à esfera institucional. Essa maleabilidade que os conceitos sugerem é interessante, especialmente para a área da comunicação, que convive com o desafio de construir um substrato teórico confiável para alicerçar o campo, mas que não desrespeite a mobilidade característica do seu objeto de estudo (Ferrara, 2010).

A despeito das semelhanças, seria imprudente e contraprodutivo igualar os conceitos, visto que cada um tem afinidade com correntes teóricas específicas e, por conseguinte, chamam a atenção para algum aspecto particular. Enquanto religiosidade midiática, de Cunha (2002), se aproxima dos Estudos Culturais e de autores como Martín-Barbero e Stuart Hall, religiosidade midiatizada vincula-se 
diretamente às pesquisas em midiatização. Com religiosidade midiática se evidencia certa estabilização das relações entre mídias e religiosidades que vêm a compor o caldo cultural da sociedade contemporânea e, portanto, constituir uma matriz de sentido pela qual o religioso se manifesta e é vivenciado. Já religiosidade midiatizada destaca o caráter processual do fenômeno, que não corresponde a um produto acabado, mas sujeito a (re)formulações a partir das ações dos sujeitos e dos campos sociais nas suas relações com o midiático, fenômenos que recobrem mudanças do religioso em diversos âmbitos (institucional, cultural e semiótico-discursivo internacional).

Não obstante tais diferenças, os conceitos não se excluem. No tocante a suas ancoragens teóricas, podem se observar aproximações diretas, como a utilização do conceito de midiatização por Cunha (2016), ou indiretas, pela articulação da discussão do conceito de midiatização com desenvolvimentos da teoria das mediações de Martín-Barbero, como faz Braga (2012) ao se referir à ênfase dada por Martín-Barbero às "mediações comunicativas da cultura" (p. 34). Mais do que diferir, os conceitos parecem ser complementares. A religiosidade midiática se constitui por meio do processo de midiatização, estabilizando-se como referência a partir da qual se constroem práticas sociais (e práticas de sentido) dos sujeitos e das organizações no tocante à dimensão religiosa do fazer social. Tal estabilidade não significa imobilidade, dada a permeabilidade midiática aos processos sociais que vêm constituir uma religiosidade em processo, uma religiosidade midiatizada.

Em outras palavras, o conceito de religiosidade midiática aponta que as transformações oriundas da midiatização da sociedade no âmbito das práticas religiosas não são pontuais, fadadas ao desaparecimento, mas da ordem da consolidação de uma cultura que referencia a vida dos sujeitos na sua relação com o religioso. Com religiosidade midiatizada se sugere que essa religiosidade midiática não se trata de um produto acabado, sendo sujeita a reformulações contínuas, dado o caráter processual próprio do fenômeno da midiatização. Por esse motivo, não faz sentido propor que um desses conceitos supera ou anula o outro. Ambos emergem em contextos teóricos distintos de maneira quase sincrônica como resultado do avanço das pesquisas em mídia e religião e colocam ênfase em diferentes aspectos de um fenômeno que poderia ser traduzido, de maneira econômica, como a consolidação de uma cultura religiosa midiática em permanente transformação.

Logo, o desafio não é a exclusão, mas sim a busca de pontos de aproximação e refinamentos desses conceitos a partir de testagens sucessivas nas pesquisas que permitiriam observar em que medida nos ajudam a responder as perguntas que fazemos aos nossos objetos. Pode-se pensar em derivações 
desses conceitos a partir de contextos específicos de análise. Desse modo, seria possível falar, sem que haja prejuízos epistemológicos, em: 1) religião midiática e religião midiatizada para focar no âmbito institucional (exemplo: sites e programas de televisão criados por instituições religiosas); 2) religiosidade midiática e religiosidade midiatizada para precisar objetos em que aspectos de institucionalidade estão presentes, mas a organização religiosa não é a responsável direta pela inserção na mídia (exemplo: grupos de oração pelo WhatsApp, páginas de leigos no Facebook); 3) espiritualidade midiática e espiritualidade midiatizada quando não se verificam aspectos institucionais (exemplo: páginas e perfis de benzedeiras e novos movimentos religiosos nas mídias digitais). $\mathrm{O}$ uso destes termos já ocorre em textos acadêmicos da área, mas ainda demanda um esforço de sistematização, o que pode ser feito em trabalhos futuros. $\mathbf{M}$

\section{REFERÊNCIAS}

Assmann, H. (1986). A igreja eletrônica e seu impacto na América Latina. Vozes.

Barka, M. B. (2000). Religion et nouvelles technologies de la communication de masse: L’exemple de l'Église électronique. Fac-Réflexion, 53(4), 30-40. https://bit.ly/2OQXijT

Belotti, K. K., \& Cunha, M. N. (2016). Mídia, religião e cultura: Percepções e tendências em perspectiva global. Prismas.

Borelli, V. (2007) Da festa ao cerimonial midiático: As estratégias de midiatização da teleromaria da Medianeira pela Rede Vida [Tese de doutorado, Universidade do Vale do Rio dos Sinos]. Repositório institucional da Unisinos. http:// bit.ly/390nfEw

Borelli, V. (2010). Mídia e religião: Entre o mundo da fé e o do fiel. E-Papers.

Braga, J. L. (2012). Circuitos versus campos sociais. In M. Â. Matos, J. Janoti Jr., \& N. Jacks (Orgs.), Mediação \& midiatização (pp. 31-52). Edufba.

Braga, J. L. (2015). Lógicas da mídia, lógicas de midiatização? In N. R. Anselmino, A. Fausto Neto, \& I. L. Gindin (Orgs.), Relatos de investigaciones sobre mediatizaciones (pp. 15-32). UNR Editora.

Bratosin, S. (2004). La concertation dans le discours du président Jacques Chirac: Sur les traces d'une representation mythique. Argumentum, (3), 11-35.

Camargo, H. W. de. (2019). Umbanda, cultura e comunicação: Olhares e encruzilhadas. Syntagma.

Campos, L. de C., Jr. (1995). Pentecostalismo: As religiões na história. Ática.

Cunha, M. N. (2002). O conceito de Religiosidade Midiática como atualização do conceito de Igreja Eletrônica em tempos de cultura gospel [Artigo apresentado]. 
XXV Congresso Anual em Ciência da Comunicação, Salvador, BA, Brasil. https://bit.ly/3r9QT0c

Cunha, M. N. (2009). Religiosidade midiática em tempos de cultura "gospel". Tempo e Presença Digital, 4(15). https://bit.ly/3vFZATH

Cunha, M. N. (2016). Elucidações contemporâneas nos estudos brasileiros em mídia e religião: A perspectiva das mediações culturais e comunicacionais. Revista Famecos, 23(2), ID22280. https://doi. org/10.15448/1980-3729.2016.2.22280

Cunha, M. N., \& Storto, L. (2020). Comunicação, linguagens e religiões. Syntagma.

Damasio, J. (2020). Da caridade à cidadania em fluxos: Posicionamentos espíritas nas Eleições 2018. Compolítica, 10(2), 135-166. https://doi.org/10.21878/ compolitica.2020.10.2.400

Deacon, D., \& Stanyer, J. (2014). Mediatization: Key concept or conceptual bandwagon? Media, Culture \& Society, 36(7):1032-1044. https://doi. org/10.1177/0163443714542218

Fausto Neto, A. (2004). Religião do contato: Estratégias dos novos "templos midiáticos". Em Questão, 2(1), 163-182. http://bit.ly/3s7vXbE

Fausto Neto, A., Gomes, P. G., Magalhães, T., \& Sbardelotto, M. (2013). Mídias e religião: A comunicação e a fé em sociedades em midiatização (2a ed.). Editora Unisinos.

Ferrara, L. D. (2010). A estratégia empírica da comunicação. In J. L. Braga, M. I. V Lopes, \& L. C. Martino (Orgs.), Pesquisa empírica em comunicação (pp. 51-69). Paulus.

Gomes, N. S.; Farina, M.; Forno, C. (2014). Espiritualidade, religiosidade e religião: Reflexão de conceitos em artigos psicológicos. Revista de Psicologia da IMED, 6(2), 107-112.

Gomes, P. G. (2010). Da igreja eletrônica à sociedade em midiatização. Paulinas. Gomes, P. G. (2016). Midiatização: Um conceito, múltiplas vozes. Revista Famecos, 23(2), ID22253. https://doi.org/10.15448/1980-3729.2016.2.22253

Gutwirth, J. (1998). Leéglise électronique : La saga des télévangélistes. Bayard.

Hanegraaff, W. J. (2017). Espiritualidades da nova era como uma religião secular: Perspectiva de um historiador (F. L. Stern \& C. Bein, trads.). Religare, 14(2), 403-424. https://doi.org/10.22478/ufpb.1982-6605.2017v14n2.37587

Hartmann, A (2002). Religiosidade midiática: Uma nova agenda pública na construção de sentidos. IHU-Online. https://bit.ly/2OStFi7

Hepp, A. (2014). As configurações comunicativas de mundos midiatizados: Pesquisa da midiatização na era da "mediação de tudo". MATRIZes, 8(1), 45-64. https://doi.org/10.11606/issn.1982-8160.v8i1p45-64 
Hepp, A., Hjarvad, S., \& Lundby, K. (2015). Mediatization: Theorizing the interplay between media, culture and society. Media, Culture \& Society, 37(2), 314-324. https://doi.org/10.1177/0163443715573835

Hjarvard, S. (2006). The mediatization of religion: A theory of the media as an agent of religious change [Artigo apresentado]. $5^{\text {th }}$ International Conference on Media, Religion and Culture: Mediating Religion in the Context of Multicultural Tension. Estocolmo, Suécia. https://bit.ly/2aUgntp

Hjarvard, S. (2014). A midiatização da cultura e da sociedade. Editora Unisinos. Klein, A., \& Camargo, H. W. de. (2017). Mitos, mídias e religióes na cultura contemporânea. Syntagma.

Marques, A. C. S., \& Guimarães, B. M. A. (2018). Conversações políticas e midiatização no Facebook: Interações e conflitos a partir dos comentários sobre as ações da Frente Parlamentar Evangélica. Intercom, 41(3), 87-103. https://doi.org/10.1590/1809-5844201835

Marques de Melo, J., Gobbi, M. C., \& Endo, A. C. B. (2007). Mídia e religião na sociedade do espetáculo. Universidade Metodista de São Paulo.

Martín-Barbero, J. (1995). Secularizacion, desencanto y reencantamiento massmediatico. Dialogos de la Comunicación, (41), 71-81. https://bit.ly/3r7eejh

Martino, L. M. S. (2012). Mediação e midiatização em suas articulações teóricas e práticas: um levantamento de hipóteses e problemáticas. In M. Â. Matos, J. Janoti Jr., \& N. Jacks (Orgs.), Mediação \& midiatização (pp. 219-244). Edufba.

Martino, L. M. S. (2014). Mediatização da religião e esfera pública nas eleições paulistanas de 2012. Revista Brasileira de Ciência Política, (14), 7-26. https:// doi.org/10.1590/0103-335220141401

Martino, L. M. S. (2015). A midiatização do campo religioso: esboço de uma síntese possível. Comunicação \& Informação (UFG), (18), 6-21.

Martino, L. M. S. (2016). Mídia, religião e sociedade: Das palavras às redes digitais. Paulus.

Miklos, J. (2010). A construção de vínculos religiosos na cibercultura: A ciberreligião. [Tese de doutorado, Pontifícia Universidade Católica de São Paulo]. Repositório institucional da PUC-SP. https://bit.ly/3s6SrcK

Patriota, K. R. P., Falcão, C. C., \& Rodrigues, E. C. B. (2016). A cartografia de um campo: Singularidades e possibilidades nas relações entre Religião e Consumo nos trabalhos desenvolvidos na comunicação [Artigo apresentado]. XXV Encontro Anual da Compós, Goiânia, GO, Brasil. https://bit.ly/2OVijtM

Patriota, K. R. P., \& Freire, A. A. (2015). O religioso na rede: Interações e discursos nas religiões 2.0. Comunicação \& Informação, 18(2), 39-21. https:// doi.org/10.5216/36820 
Reblin, I. A. (2012). A superaventura: Da narratividade e sua expressividade à sua potencialidade teológica [Tese de doutorado, Escola Superior e Teologia]. Repositório institucional das Faculdades EST. https://bit.ly/3f0yq3K

Rodrigues, D. A. (2019, maio-agosto). Caminhar com fé: Estudo sócio-antropológico de uma peregrinação ao Santuário de Fátima, Portugal. Estudos de Religião, 33(2), 181-196.

Rosa, A. C. P. F. da (2018). A internet dos leigos: Catolicismo midiático e práticas de consumo como experiência vivida [Tese de doutorado, Universidade Federal de Santa Maria]. Repositório institucional da UFSM. https://bit.ly/3c5sa8Z

Sbardelotto, M. (2012, 12-15 junho). Dos bits à rede: Entre a experiência religiosa e a representação social do "católico" na internet [Artigo apresentado]. XXI Encontro Anual da Compós, Juiz de Fora, MG, Brasil. https://bit.ly/3c8MtT6 Sbardelotto, M. (2014, 27-30 maio). O leigo-amador no contexto da midiatização: Uma análise da circulação do "religioso" na internet [Artigo apresentado]. XIII Encontro Anual da Compós, Belém, PA, Brasil. https://bit.ly/2OZLhIO

Sousa, M. T. de. (2014). As narrativas do reino: Análise narrativa de programas televisivos da Igreja Universal nas madrugadas mineiras [Dissertação de mestrado, Universidade Federal de Minas Gerais, Belo Horizonte]. Repositório institucional da UFMG. https://bit.ly/30ZT8ZB

Sousa, M. T. de. (2018a). Bençãos e exorcismos midiáticos: A emergência de pontos de sacralização na programação televisiva da Igreja Universal nas madrugadas. In: C. A. Barbosa (Org.), Discursividade pentecostal II: A voz da mídia é a voz de Deus? (pp. 65-95). Reflexão.

Sousa, M. T. de. (2018b). Rezando pelo smartphone: Reconfigurações de práticas religiosas em um grupo de oração católico pelo WhatsApp. Revista Fronteiras, 20(2), 217-230. https://doi.org/10.4013/fem.2018.202.07

Spadaro, A. (2012). Ciberteologia: Pensar o Cristianismo em tempos da rede. Paulinas.

Tudor, M. A., \& Herteliu, A. M. (2017). Léglise connectée: Le cas de la plateforme Jesus Market. Revue des sciences religieuses, 91(4), 589-604. https:// doi.org/10.4000/rsr.3564

Artigo recebido em 29 de maio de 2020 e aprovado em 16 de fevereiro de 2021. 